\title{
Axonal Stress Kinase Activation and Tau Misbehavior Induced by Kinesin-1 Transport Defects
}

\author{
Tomás L. Falzone, ${ }^{1 \star}$ Gorazd B. Stokin, ${ }^{3 \star}$ Concepción Lillo, ${ }^{2}$ Elizabeth M. Rodrigues, ${ }^{1}$ Eileen L. Westerman, ${ }^{1}$ \\ David S. Williams, ${ }^{2}$ and Lawrence S. B. Goldstein ${ }^{1}$ \\ ${ }^{1}$ Howard Hughes Medical Institute, Department of Cellular and Molecular Medicine, and 2Department of Pharmacology, School of Medicine, University of \\ California, San Diego, La Jolla, California 92093, and ${ }^{3}$ Division of Neurology, University Medical Center and Department of Gerontopsychiatry, University \\ Psychiatric Hospital, SI-1000 Ljubljana, Slovenia
}

\begin{abstract}
Many neurodegenerative diseases exhibit axonal pathology, transport defects, and aberrant phosphorylation and aggregation of the microtubule binding protein tau. While mutant tau protein in frontotemporal dementia and parkinsonism linked to chromosome 17 (FTDP17) causes aberrant microtubule binding and assembly of tau into filaments, the pathways leading to tau-mediated neurotoxicity in Alzheimer's disease and other neurodegenerative disorders in which tau protein is not genetically modified remain unknown. To test the hypothesis that axonal transport defects alone can cause pathological abnormalities in tau protein and neurodegeneration in the absence of mutant tau or amyloid $\beta$ deposits, we induced transport defects by deletion of the kinesin light chain 1 (KLC1) subunit of the anterograde motor kinesin-1. We found that upon aging, early selective axonal transport defects in mice lacking the KLC1 protein $(\mathrm{KLC} 1-/-)$ led to axonopathies with cytoskeletal disorganization and abnormal cargo accumulation. In addition, increased c-jun $\mathrm{N}$-terminal stress kinase activation colocalized with aberrant tau in dystrophic axons. Surprisingly, swollen dystrophic axons exhibited abnormal tau hyperphosphorylation and accumulation. Thus, directly interfering with axonal transport is sufficient to activate stress kinase pathways initiating a biochemical cascade that drives normal tau protein into a pathological state found in a variety of neurodegenerative disorders including Alzheimer's disease.
\end{abstract}

\section{Introduction}

Neurodegeneration associated with aberrant tau phosphorylation is coupled to the pathological destabilization of microtubules, formation of intracellular paired helical filaments (PHF) and neurofibrillary tangles (NFT) (Goedert and Spillantini, 2006; Ballatore et al., 2007). In FTDP17, both loss and toxic gain of function of mutant tau protein (Hutton et al., 1998; Spillantini et al., 1998) result in a reduction of microtubule binding affinity and increased assembly of tau into abnormal filaments (Nacharaju et al., 1999; Barghorn et al., 2000). However, the initial pathways that lead to tau-dependent neurotoxicity in Alzheimer's disease $(\mathrm{AD})$, progressive supranuclear palsy, corticobasal degeneration and other sporadic diseases are unknown. The

\footnotetext{
Received Feb. 13, 2009; revised March 23, 2009; accepted March 31, 2009.

This work was supported by National Institutes of Health Grants GM35252 (L.S.B.G.) and EY07042 (D.S.W.). T.L.F. received support from the Pew Latin American Program and the American Parkinson Disease Association; G.B.S from Boehringer-Ingelheim Fonds. L.S.B.G. is an Investigator of the Howard Hughes Medical Institute. We thank Eliezer Masliah for helpful comments on data interpretation, the manuscript, and for providing control human AD brain tissue; Christine Vande-Velde for the MITO-EGFP plasmid; Peter Davies for helpful discussions and providing tau antibodies; Ximena Pastorino for constant support; and Drs. Almenar-Queralt, Gunawardena, Encalada, Schimmelpfeng, Weaver, Duncan, and Bache and all members of the Goldstein laboratory for helpful discussion on data interpretation and presentation.

${ }^{*}$ T.L.F. and G.B.S. contributed equally to this work.

Correspondence should be addressed to Dr. Lawrence S. B. Goldstein, University of California, San Diego, 9500 Gilman Drive, Leichtag Biomedical Research Building, La Jolla, CA 92093-0683. E-mail: Igoldstein@ucsd.edu.

C. Lillo's present address: Departamento de Biología Celular y Patología, Facultad de Medicina, Universidad de Salamanca, 37007 Salamanca, Spain.

DOI:10.1523/JNEUROSCI.0780-09.2009

Copyright $\odot 2009$ Society for Neuroscience $\quad 0270-6474 / 09 / 295758-10 \$ 15.00 / 0$
}

combined action of several kinases leads to tau phosphorylation at $>20$ residues and in different subcellular compartments (Hanger et al., 1998; Buée et al., 2000). Among these kinases, axonal stress activated kinases can phosphorylate tau in vivo and in vitro (Goedert et al., 1997; Reynolds et al., 1997; Chang et al., 2003; Yoshida et al., 2004), and c-jun N-terminal stress kinase (JNK) deposits that precede tau inclusions have been suggested to be caused by early signaling deregulation events in the pathological cascade of cytoskeletal disorganization (Atzori et al., 2001; Lagalwar et al., 2006). The possibility that axonal transport impairments might induce the initiating events that lead to stress kinase activation and tau pathology has been suggested by two recent findings: (1) KLC1 reduction can exacerbate axonal pathologies and amyloid $\beta(\mathrm{A} \beta)$ plaque deposition in mouse models of AD generated by amyloid precursor protein (APP) overexpression (Stokin et al., 2005), and (2) axonal transport mediates stress kinase signaling induced by neuronal damage (Cavalli et al., 2005).

As a microtubule binding protein, tau is important for regulating kinesin and dynein microtubule-based axonal transport of cytoskeletal and synaptic cargos (Goldstein, 2003; De Vos et al., 2008; Dixit et al., 2008). The anterograde motor complex kinesin-1, formed by the association of two heavy chains and two light chains, powers the transport of cargos such as APP, JNK interacting proteins, and Alcadein to the synapse (Bowman et al., 2000; Kamal et al., 2000; Verhey et al., 2001; Araki et al., 2007). Not only is tau important for microtubule-based transport which in turn is essential for axonal and synaptic integrity, but also 
excess tau inhibits anterograde organelle and vesicular transport in axons (Stamer et al., 2002). Furthermore, axonal protein accumulation, neuritic swellings and white matter degeneration are hallmarks of transport defects and abnormally phosphorylated tau (Higuchi et al., 2002; McGowan et al., 2006; De Vos et al., 2008). In $\mathrm{AD}$ and animal models of $\mathrm{AD}$, phenotypes suggestive of axonal transport defects occur early, before, and/or distant from, sites of A $\beta$ deposition (Stokin et al., 2005). Such defects in mouse and Drosophila are enhanced by reduction of kinesin-1 function (Gunawardena and Goldstein, 2001; Stokin et al., 2005), and may be associated with accumulation of phosphorylated tau (Stokin et al., 2005). Because increased APP gene dose can cause AD in humans (Rovelet-Lecrux et al., 2006), and can also cause transport defects in Drosophila and mouse that are independent of A $\beta$ toxicity (Gunawardena and Goldstein, 2001; Stokin et al., 2008), a key question is whether transport defects can cause aberrant tau phosphorylation and conformation in the absence of $\mathrm{A} \beta$ induced neurotoxicity. To test whether impaired axonal transport is sufficient to cause tau-associated pathology, we analyzed transport defects and neuronal pathologies in mice lacking the KLC1 subunit of kinesin-1 (Rahman et al., 1999).

\section{Materials and Methods}

Mice. KLC1-/- mice from a mixed 129/C57BL/6J background (Rahman et al., 1999) were backcrossed into pure C57BL/6J for 12 generations and $\mathrm{KLC1}+/-$ were crossed with each other to obtain wild type and KLC1-/-. Genotyping was performed by PCR amplification of wildtype and recombinant KLC1 alleles (Rahman et al., 1999).

Antibodies. The following monoclonal antibodies were used: MAP2 (Millipore Bioscience Research Reagents); p-NF (Sternberger Monoclonals); tubulin (Sigma); p-GSK3 $\beta$ (p-Y216), Drosophila Syntaxin (Hybridoma Bank); $\alpha$-synuclein and JNK1/2 (BD Biosciences); and synaptotagmin (Bellen). Polyclonal antibodies included APP, ubiquitin, and ChAT (Millipore Bioscience Research Reagents); CDK5, phosphorylated JNK (p-JNK), and P35 (Cell Signaling). We also used the following antitau antibodies: TAU-5 (Biosource); AT-8 (Pierce); PHF13 (Covance); and anti-p-tau:PHF1, CP13, TG3, and MC1 from P. Davies (Albert Einstein College of Medicine, Bronx, NY).

Statistical analysis. Averages are plotted in each graph and error bars represent the SEM. Asterisks indicate significance. For brain and spinal cord stereology, nonparametric statistical test were used. As indicated, one-way Kruskal-Wallis test or Mann-Whitney (two-sample rank sum) was used to analyze total brain, corpus callosum, and spinal cord volumes, and motor neuron counts. Student's $t$ test was used to determine significance between $\mathrm{KLC} 1-/-$ and wild type in particle-tracking analysis and axonal frequencies and to compare fluorescent intensity levels in quantitative Western blot analyses. Normal distribution was assayed for each group, and a two-tailed Student's $t$ test was used. Smirnov-Kolmogorov test was used to analyze cumulative speed frequencies distribution for app-yfp vesicles.

Primary hippocampal cultures. Newborn hippocampal brain regions from KLC1 $+/-$ crosses were dissected on postnatal day 1 . Treated independently, hippocampi were incubated in $0.22 \mu \mathrm{m}$-filtered mixture of 45 $\mathrm{U}$ of papain (Worthington) in PBS, DL-cysteine (Sigma), and BSA and glucose (Sigma) enriched with $0.05 \%$ of DNase (Boehringer Mannheim) for $30 \mathrm{~min}$ at $37^{\circ} \mathrm{C}$. Hippocampi were triturated by carefully pipetting in $10 \% \mathrm{FBS} / \mathrm{DMEM}$. Cells were grown in $500 \mu \mathrm{M} \mathrm{L}$-glutamine and Neurobasal media supplemented with B27 (Invitrogen) over poly-D-lysinecoated coverslips. pcdna3 CMV-APP-YFP (Kaether et al., 2000) containing a protein fusion between $\mathrm{APP}^{695}$ and yellow fluorescent protein (YFP) was used for transfection between days 4 and 10. pcdna3 CMVMITO-EGFP (C. Vande Velde, University of California, San Diego, La Jolla, CA) containing the enhanced green fluorescent protein (EGFP) fused to a mitochondrial signal peptide from the human cytochrome $\mathrm{C}$ was transfected after $4 \mathrm{~d}$. Low transfection efficiency was obtained using Lipofectamine 2000 (Invitrogen).

Movies and kymograph analysis. APP-YFP or MITO-EGFP movement was registered in transfected primary cultures (Koo et al., 1990; Glater et al., 2006) using an inverted epifluorescent microscope (TE-2000U, Ni-

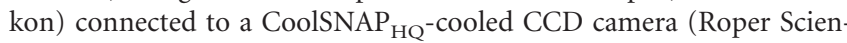
tific) and driven by MetaMorph 7.0 (Universal Imaging Corporation). Cultures were kept under a $100 \times$ lens at $37^{\circ} \mathrm{C}$ using a heating stage and in $5 \% \mathrm{CO}_{2}$ chamber (Harvard Apparatus). Sixteen to twenty-four hours after transfection, cells were registered. Directionality was determined by tracking axons far away from cell bodies and imaging at their middle part. Particles moving from cell body to axon tips were considered anterograde and from tips to cell bodies retrograde. Continuous $15 \mathrm{~s}$ stacks (150 frames) at a speed of $100 \mathrm{~ms}$ were collected for APP-YFP (Kaether et al., 2000). Time-lapse of $100 \mathrm{~ms}$ frames every $5 \mathrm{~s}$ for $10 \mathrm{~min}$ (120 frames) were collected for MITO-EGFP (Glater et al., 2006). Kymographs were plotted and average speed, distance, and directionality were extracted for analyses.

Stereology. Stereology measurements were obtained with a light microscope Axioplan Zeiss associated with a Bioquant Nova image analysis system (Bioquant R\&M Biometrics). In brief, volume estimated from brain and cervical cord were determined using 10 systematic random serial sections of $50 \mu \mathrm{m}$ slices (Long et al., 1999; Mouton, 2002). Slices were selected randomly together with another nine sections spaced apart by $500 \mu \mathrm{m}$ (Long et al., 1999; Mouton, 2002). Cavalieri's principle was used for an unbiased estimation of an arbitrary shape volume. $V_{\text {Cavalieri }}=$ $t\left(A_{1}+A_{2}+\ldots+A_{\mathrm{p}}\right)$ (Mouton, 2002; Duerstock et al., 2003). Volumes were obtained from the product of the distance between analyzed planes $(t)$ and the sum of registered areas on systematic-random sections (Sum A) (Mouton, 2002). Motor neuron numbers were estimated using the optical fractionator method, $N=\Sigma Q^{-}$(1/ssf)(1/asf)(1/tsf). Random serial sections were analyzed using Bioquant. Section sampling fraction (ssf) is the number of sections sampled divided by the total number of sections (10/100); area sampling fraction (asf) is the area of sampling frame divided by the area of the $x-y$ sampling step $=1$; and thickness sampling fraction (tsf) is the height of the disector divided by the section thickness $=1$. Criteria for profile counting required that cell bodies exhibited positive ChAT immunoreactivity and morphological features consistent with motor neurons. Axonal root numbers and diameters were obtained from $1 \mu \mathrm{m}$ Epon sections of L5 lumbar roots stained with toluidine blue using Bioquant. Cross-sectional area of each axon was converted to diameter of a circle of equivalent area.

Protein quantification. Secondary fluorescent-labeled antibodies were used in Western blot analyses for quantification. SDS-PAGE protein gels were transferred to nitrocellulose and blocked, and washes were performed in the absence of Tween detergent to decrease background. Secondary antibodies coupled to $800 \mathrm{~nm}$ and $700 \mathrm{~nm}$ infrared fluorophore were used in combination to detect levels of p-JNK and total JNK in the same membrane. Protein concentration curves were loaded and secondary antibodies used to detect respective antibodies affinities and to observed linearity detection using this technique. Odyssey imaging system scanner (Li-Cor) was used to measure fluorescence intensity.

Immunoelectron microscopy. Hippocampal and ventral regions of the spine were cut in several small pieces and processed for embedment in LR White resin (Electron Microscopy Sciences). Ultrathin sections were incubated with mab AT-8 (Pierce) (1:20) overnight at $4^{\circ} \mathrm{C}$, incubated with goat anti-mouse IgG conjugated to $6 \mathrm{~nm}$ gold (Aurion, Electron Microscopy Sciences), and silver enhanced with Aurion R-Gent SE-EM (Electron Microscopy Sciences). Sections were later stained with 2\% ethanolic uranyl acetate for $15 \mathrm{~min}$ and lead citrate for $10 \mathrm{~min}$ before observation in the electron microscope.

\section{Results \\ Early selective axonal transport defects induced by KLC1 deletion}

The neuronally enriched KLC1 motor subunit associates with the force-generating kinesin heavy chain subunit to mediate the transport of many vesicular and protein cargos (Rahman et al., 1999). Although, it has been shown that APP depends on KLC1 for normal localization and processing in neurons (Stamer et al., 2002; Stokin et al., 2005), it is not clear whether loss of KLC1 in 
early neuronal stages results in general impairment of overall transport, or only in selective defects within KLC1-dependent pathways. To test how neuronal deletion of KLC1 may impair transport we characterized the axonal dynamics of two distinct cargos with potentially different dependencies upon KLC1. Cultured primary hippocampal neurons from wild type and KLC1-/- showed similar polarization and no obvious differences in neurite extension or branching (data not shown). Polarized mature neurons were transiently transfected with fluorescent fusion proteins to compare the KLC1-dependent fast axonal transport of APP vesicles (APPYFP) (Kaether et al., 2000; Kamal et al., 2000), to the slower KLC1-independent mitochondrial transport (MITO-EGFP) (Hollenbeck and Saxton, 2005; Glater et al., 2006) (Fig. 1a,g; supplemental Fig. 1, available at www.jneurosci.org as supplemental material). Deletion of KLC1 induced axonal transport defects of APPYFP vesicles, including a significant decrease in the proportion of particles moving in the anterograde direction (Fig. $1 b)$, an increase in the number of retrograde particles (Fig. 1b), and a reduction in net velocity and average run length for anterograde and retrograde APP-YFP particles (Fig. $1 c-f$ ). In contrast, when we evaluated the axonal movement of mitochondria in neurons transfected with MITO-EGFP, we observed equivalent proportions of anterograde, stationary, and retrograde mitochondrial particles across genotypes (Fig. 1h). Furthermore, velocities and run length of axonal anterograde and retrograde mitochondria in KLC1-/ - were comparable to those of wild type (Fig. 1i,j). Thus, KLC1 deletion does not impair hippocampal neuron development and polarization, or mitochondrial transport, in culture. However, loss of KLC1 causes early and selective axonal transport defects of APP vesicles.

Age-dependent brain and spinal cord axonopathies induced by KLC1 deletion in mice

Axonal atrophy in the hippocampus and corpus callosum are features of the neurodegenerative process affecting neuronal connectivity in AD brains (Rose et al., 2000; Teipel et al., 2003; Xie et al., 2006). Thus, given the proposed connections between axonal transport defects and $\mathrm{AD}$ and to understand the consequences of early selective axonal transport impairments in the mouse brain, we characterized the age-dependent neuronal phenotypes induced by KLC1 deletion. Initial examination of neuronal integrity in $\mathrm{KLCl}-/-$ mice revealed normal overall organization of cortical layers and neuronal structures in young animals. However, as animals aged, axonal degeneration was observed in axonenriched structures (Fig. 2a,b) including the corpus callosum
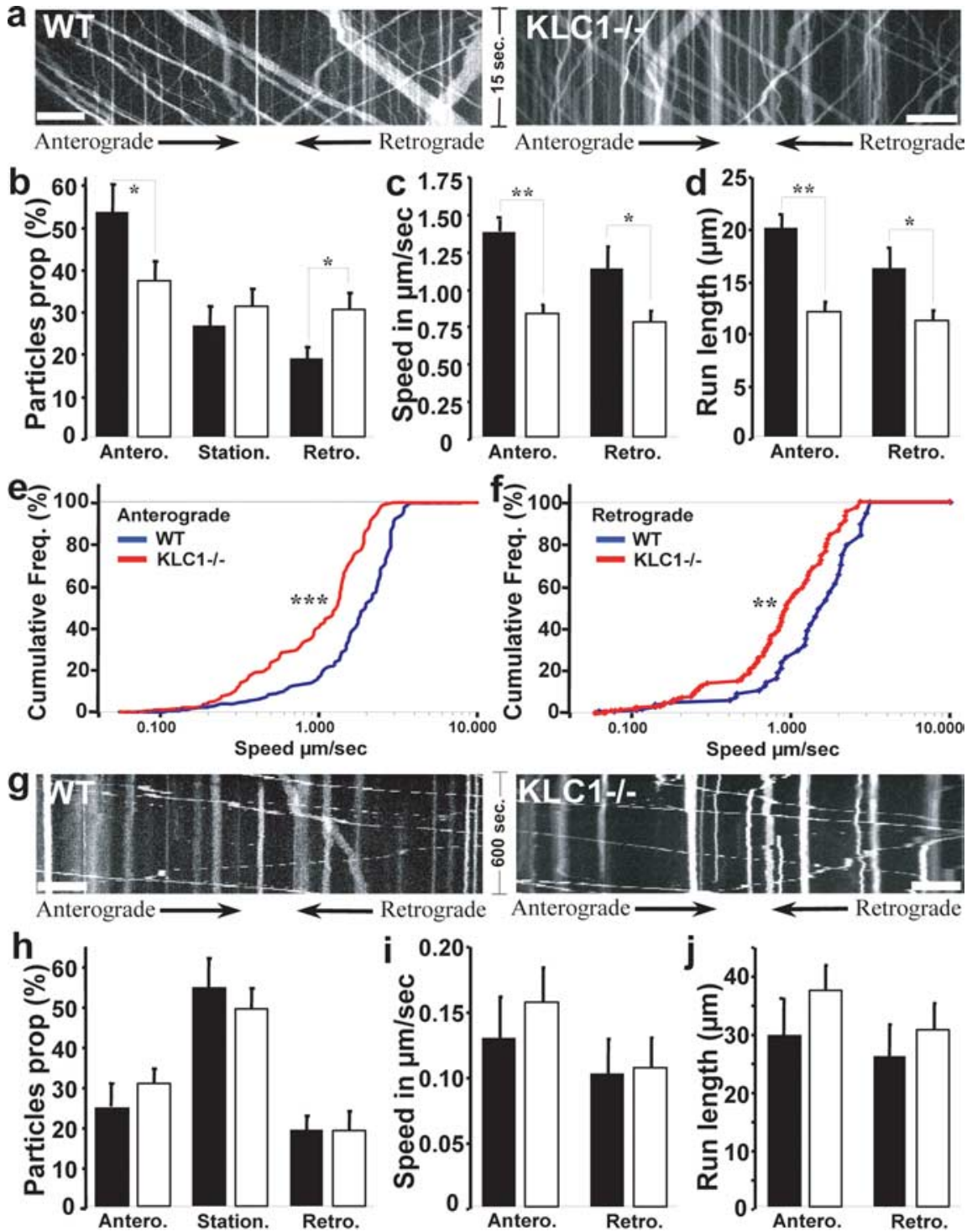

Figure 1. Early selective axonal transport defects in $K L C 1-1-$ primary hippocampal neurons. a, Kymographs of APP-YFP or left descending particles equal anterograde or retrograde moving vesicles, respectively. Vertical lines equal stationary particles. Scale bar, $10 \mu \mathrm{m} . \boldsymbol{b}$, Average frequency of anterograde, stationary, and retrograde APP-YFP particles for WT (black) and run length ( $\boldsymbol{d}$ ) of APP-YFP anterograde and retrograde particles obtained from kymograph analyses $\left({ }^{*} p<0.05,{ }^{* *} p<0.02\right)$. Anterograde $(\boldsymbol{e})$ and retrograde $(\boldsymbol{f})$ cumulative velocity distribution showing slower APP-YFP movement velocities in $K L C 1-1-$ obtained from $600 \mathrm{~s}$ time-lapse movies (supplemental Fig. 1b, available at www.jneurosci.org as supplemental material). Scale bar, $10 \mu \mathrm{m}$. $\boldsymbol{h}$, Average frequency of anterograde, stationary, and retrograde MITO-EGFP particles for WT (black) and KLC1 - /(white). Average net speed (i) and run length (j) of anterograde and retrograde MITO-EGFP obtained from kymograph analyses.

(Fig. 2a,c) and the anterior commissure of the brain (data not shown). Moreover, KLC1-/- hippocampal regions had striking axonal pathologies characterized by increased immunoreactivity for phosphorylated neurofilaments ( $\mathrm{p}-\mathrm{NF}$ ) in the dentate gyrus and the CA1 region in 18-month-old mice (Fig. 2f). Bielschowsky's silver staining of swollen projections and spheroid structures in the CA3 region of aged $\mathrm{KLC1}-/-$ brains (Fig. $2 g$ ) suggests the accumulation of argyrophilic materials within degenerating axons.

Because prominent axonopathies with abnormal tau accumulation and pronounced neuron degeneration are observed in motor neurons in transgenic mouse models of tauopathies (Ishihara 


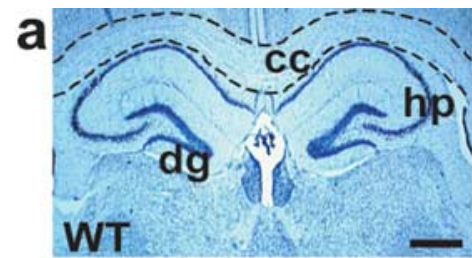

C

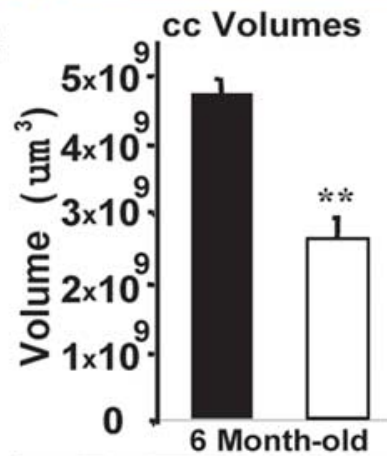

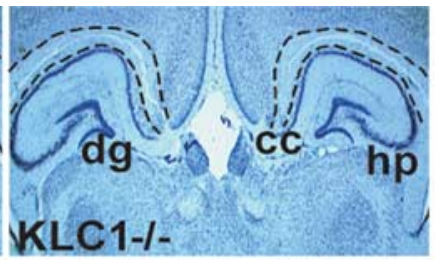

d $20 \times 10^{9}$ Spinal Cord Volumes

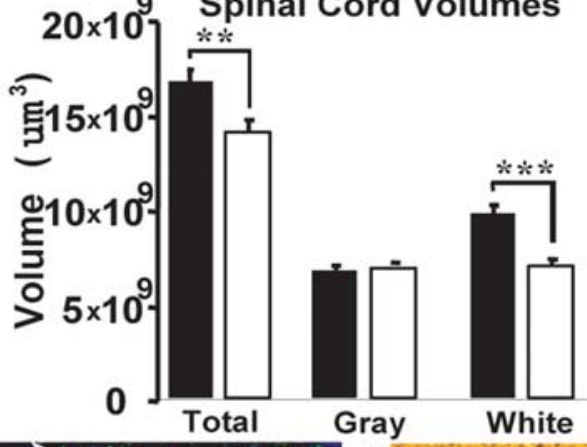

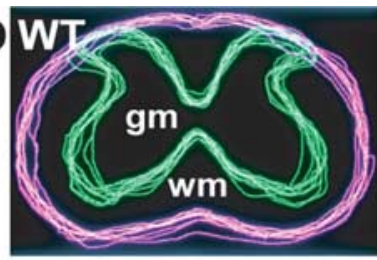

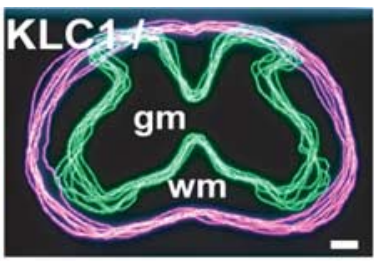

e
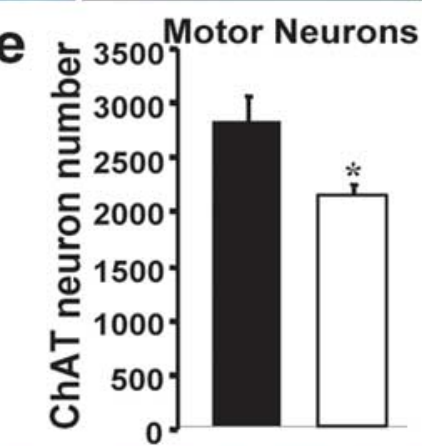
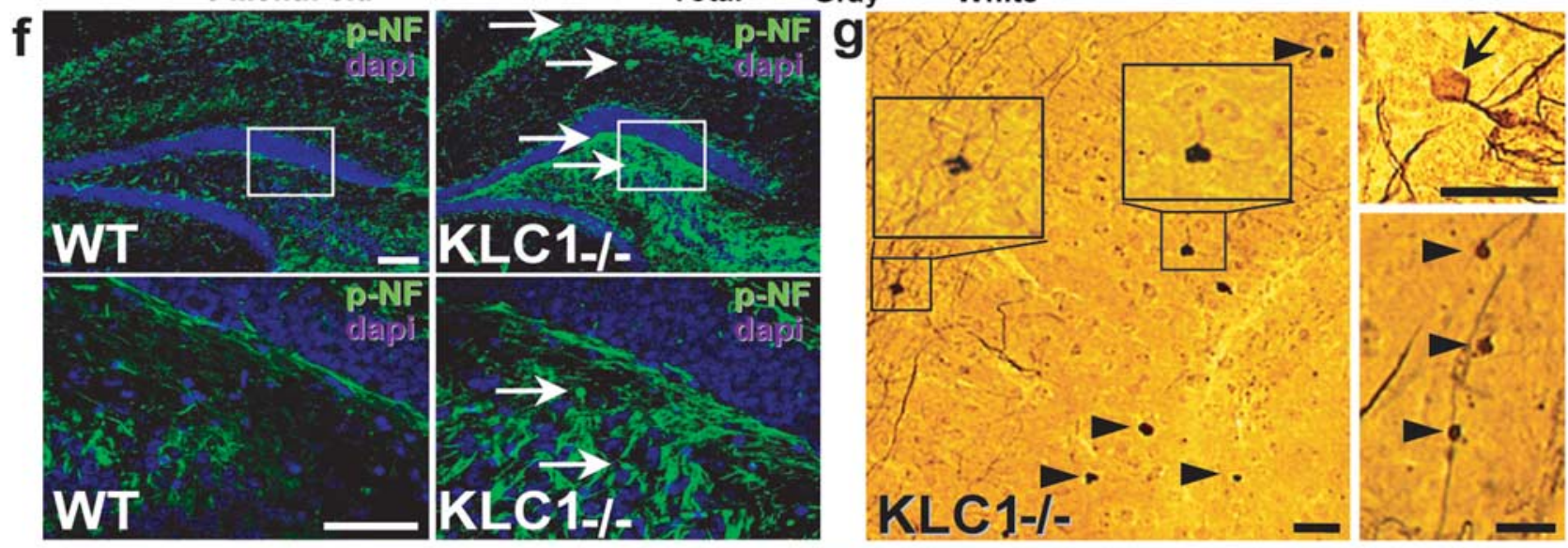

h

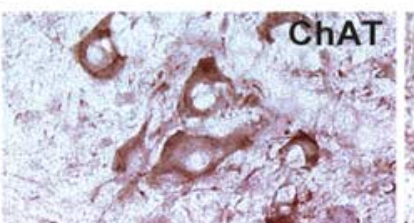

WT $\quad$ - KLCI-
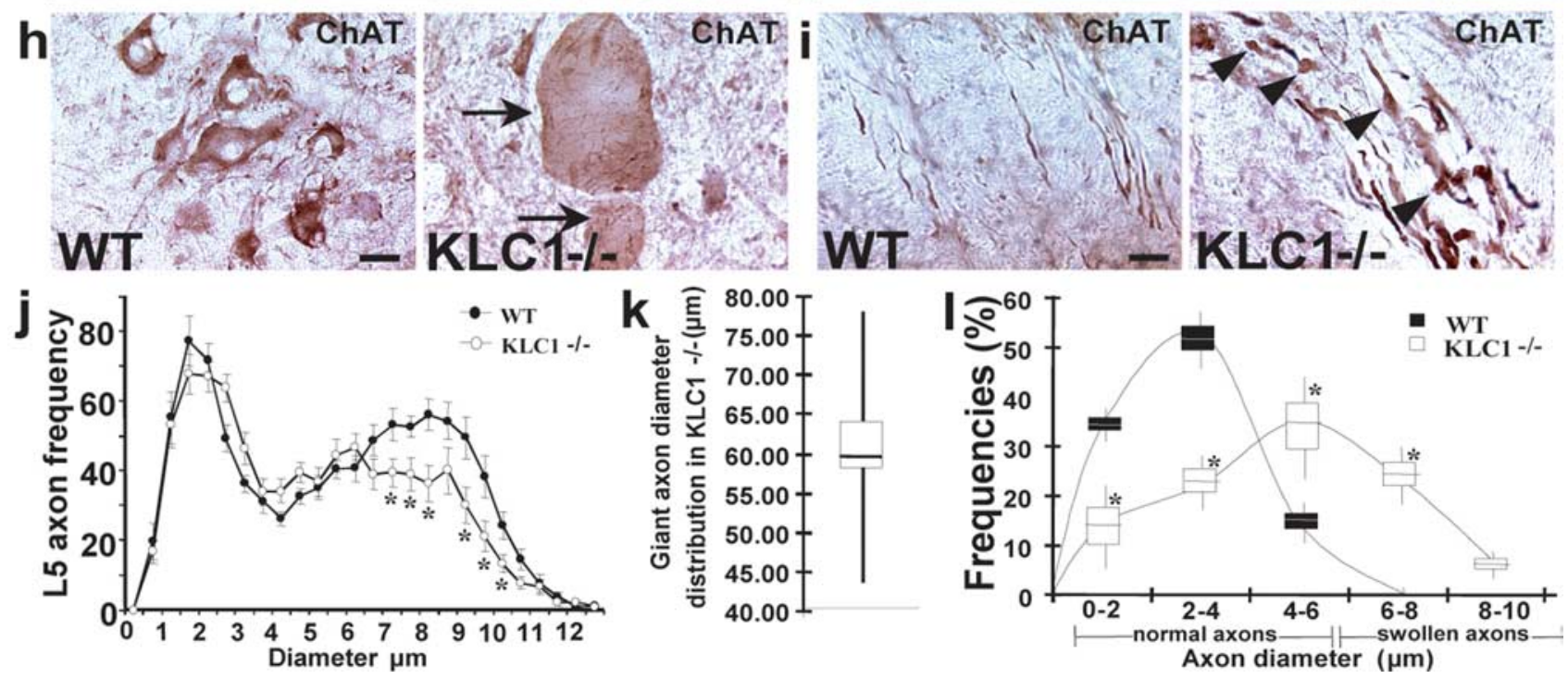

Figure 2. Axonopathies in the brain and spinal cord of $K L C 1-/-$ mice. $a$, Eighteen-month-old wild-type (WT) and $K L C 1-/-$ brain sections stained with thionin. Note reduction of axon bundles in the corpus callosum (cc) in KLC1-/- (hp, hippocampus; dg, dentate gyrus). Scale bar, $500 \mu \mathrm{m}$. $\boldsymbol{b}$, Gray (gm) and white matter (wm) from a 12-slice montage of 18-month-0ld cervical spinal cord. Note wm reduction in KLC1-I-. Scale bar, $200 \mu$ m. c, d, WT (black) and KLC1-/- (white) corpus callosum and spinal cord volumes estimated using Cavalieri's principle. c, cc volumes from young mice (Kruskal-Wallis test; $n=3$ per genotype, ${ }^{* *} p<0.02$ ). $\boldsymbol{d}$, Total, gm, and wm volumes from 18 -month-old spinal cords. $\boldsymbol{e}$, Motor neuron number from aged cervical spinal cord estimated using the optical fractionator method (Mann-Whitney test; $n=5$ per genotype, ${ }^{*} p<0.05,{ }^{* *} p<0.02,{ }^{* * *} p<0.002$ ). $f$, Immunofluorescent staining of 18-month-old hippocampus for $p$-NF and nuclei (DAPI). Note abnormal accumulation of p-NF within axonal swellings in KLC1 - / - (arrows) magnified from above insets. Scale bar, $50 \mu \mathrm{m} . \boldsymbol{g}$, Bielschowlski's silver stained argyrophilic cell bodies (arrow, top right), and spheroids and swellings (arrowheads, left and bottom right) within projections in CA3 region of KLC1-/ - brain. Scale bars, $20 \mu \mathrm{m}$. $\boldsymbol{h}, \boldsymbol{i}$, ChAT immunohistochemistry in ventral horns ( $\boldsymbol{h}$ ) and motor roots (i) from cervical spinal cords.

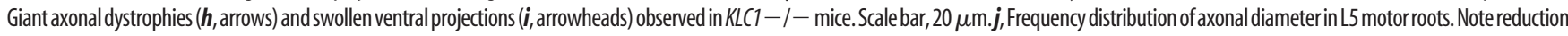
of large caliber axon frequencies in $K L C 1-I-$ (Student'st test; WT, $\left.n=9 ; K L C 1-I-, n=10 ;{ }^{*} p<0.05\right)$. $\boldsymbol{k}$, Diameter distribution of giant axonopathies in $K L C 1-I-$ ventral horns. I, Frequency distribution of axonal diameter from cervical ventral roots ( $\chi^{2}$ distribution test; WT, $n=4 ; K L C 1-1-, n=6 ;{ }^{*} p<0.05$ ). 


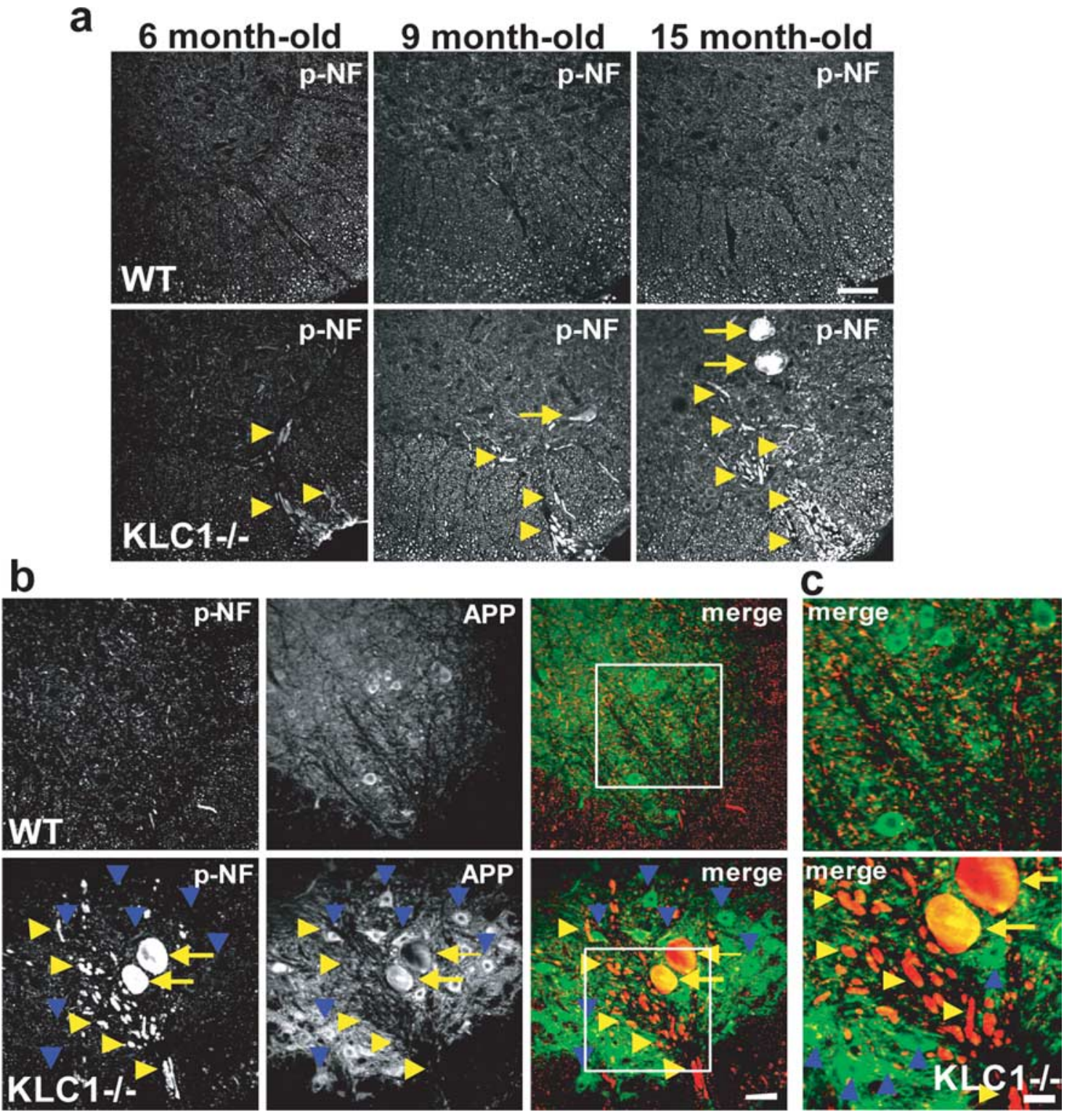

Figure 3. Age-dependent increase of spinal cord axonal pathologies accumulating neurofilaments and APP. $\boldsymbol{a}$, Confocal images showing staining for $\mathrm{p}$-NF in ventral regions of the spinal cord in wild type and $K L C 1-I-$ at 6,9 , and 15 month of age. Note increase in giant dystrophies (arrows) and swollen ventral projections (arrowheads) that accumulate $\mathrm{p}-\mathrm{NF}$ immunoreactivity as animal ages. Scale bar, $100 \mu \mathrm{m} . \boldsymbol{b}$, Giant axonopathies (arrows) and swollen ventral projections (yellow arrowheads) showing the colocalization of p-NF and APP in 18-month-old KLC1 - / - spinal cord. Note absence of p-NF staining in KLC1-I- cell bodies (blue arrowheads). Scale bar, $50 \mu \mathrm{m}$. c, Magnifications from insets. Scale bar, $20 \mu \mathrm{m}$.

et al., 1999; Spittaels et al., 1999; Lewis et al., 2000; Lin et al., 2005; McGowan et al., 2006), we tested whether similar pathologies were found in $\mathrm{KLC} 1-/-$ mice. Interestingly, a significant increase in progressive age-dependent proximal swellings was observed in $\mathrm{KLC} 1-/-$ cervical spinal cords at different ages (Fig. $3 a)$. As in the brain, significant reductions in the white matter of the spinal cord (Fig. 2b,d), and reduction of large caliber axons in peripheral motor roots (Fig. $2 j$ ) were observed in aged KLC1 - /mice. The absence of $\mathrm{p}-\mathrm{NF}$ accumulation in cell bodies suggests that neurofilaments were delivered into axons before phosphorylation and accumulation. Interestingly, two different types of axonal pathologies were frequently seen in ventral regions of the spinal cord after p-NF and APP staining in aged mice (Fig. $3 b, c$ ). One type corresponds to giant axonal enlargements (dystrophies) showing average diameters of $60 \mu \mathrm{m}$ and located proximal to motor neuron cell bodies (Fig. $2 h, k$ ). The other type corresponds to abnormal axonal swellings in ventral axonal roots of the spinal cord with shifts in diameter distribution to distended projections compared with wild type (Fig. 2i,l). Giant axonal dystrophies and swollen ventral projections were also stained by antibodies recognizing the motor neuron marker choline acetyltransferase (ChAT) (Fig. 2h,i) and together with the observed motor neuron loss (Fig. 2e) suggest significant cholinergic degeneration in $K L C 1-/-$ cervical spinal cord.

Organelle accumulation and cytoskeletal disorganization in axonal swellings

Axonal microtubule destabilization and physical blockage of axons has been suggested to be part of the neurodegeneration mechanism in tau-related diseases (Ballatore et al., 2007). Thus, to test for cytoskeletal disorganization, and accumulation of vesicles and organelles similar to the axonal defects found in tauopathies (Higuchi et al., 2002), we performed ultrastructural characterization of axonal pathologies in 18-month-old KLC1-/- 

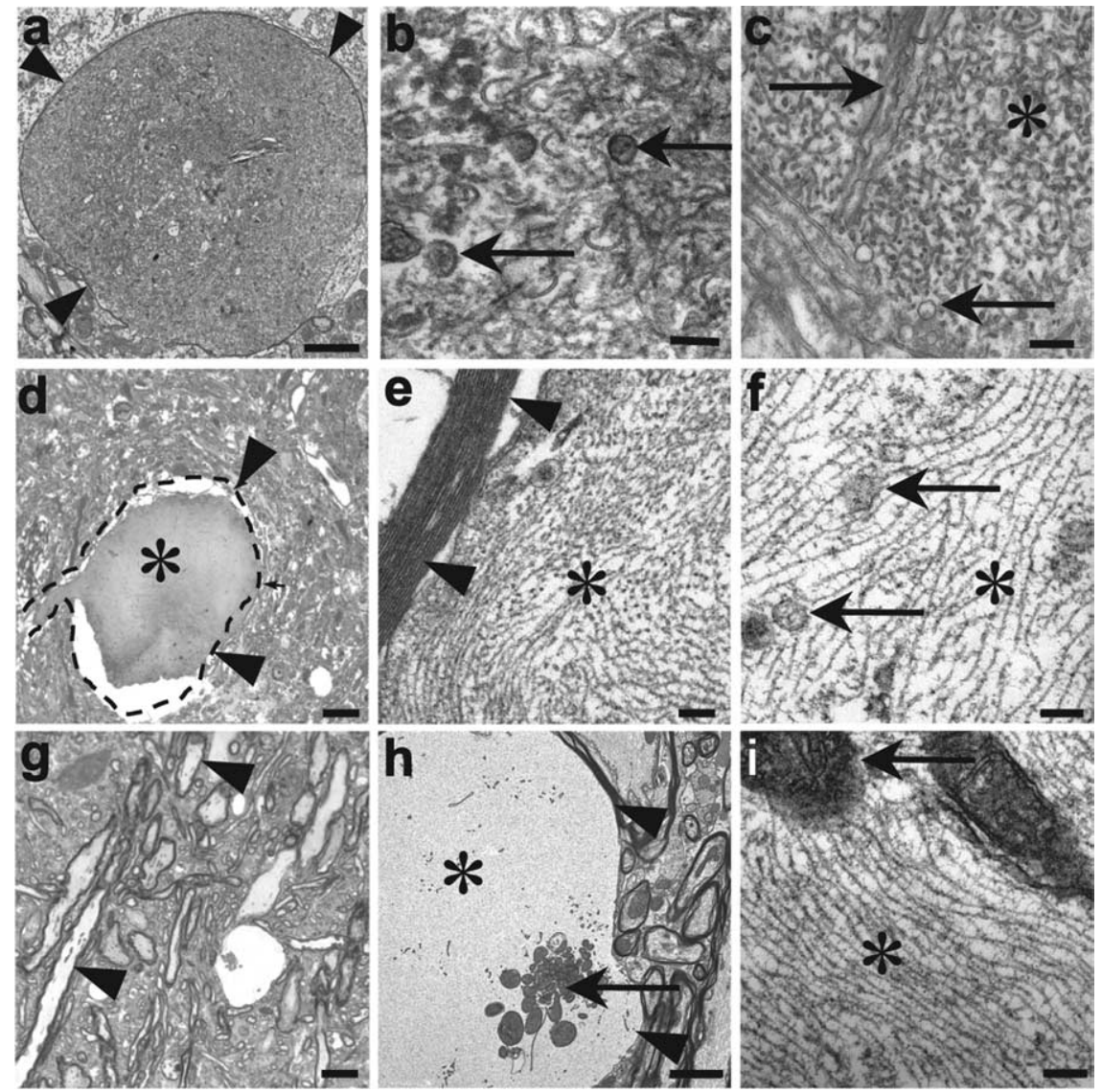

Figure 4. Cystoskeletal disorganization and organelle accumulation in brain and spinal cord axonopathies. $\boldsymbol{a}-\boldsymbol{c}, K L C 1-/-$ hippocampal axonal swellings surrounded by myelin (arrowheads) are in c, loaded with membrane stacks and tubuloreticular structures (arrows) observed among filamentous accumulations (asterisk). $\boldsymbol{b}$, Vesicles, collapsed membranes and organelle buildup (arrows) inside a CA3 axonal swelling. $\boldsymbol{d}-\mathbf{f}$, Giant axonal dystrophies surrounded by thin myelin layer (arrowheads) and massive accumulation of dense neurofilament networks (asterisk) with intermingled vesicles (arrows). $\boldsymbol{g}-\boldsymbol{i}$, Ventral roots with abundant axonal swellings accumulating similar dense filament (asterisk) and mitochondria (arrows). Scale bars: $\boldsymbol{a}, \boldsymbol{h}, 1 \mu \mathrm{m} ; \boldsymbol{d}$, $10 \mu \mathrm{m} ; \boldsymbol{g}, 5 \mu \mathrm{m} ; \boldsymbol{b}, \boldsymbol{c}, \boldsymbol{e}, \boldsymbol{f}, \boldsymbol{i}, 100 \mathrm{~nm}$.

mice. Hippocampal regions harbored swollen and distended axons containing disrupted microtubule networks, anomalous tubuloreticular structures, and atypical accumulations of membrane stacks in distended neurites (Fig. $4 a, c$; supplemental Fig. 2, available at www.jneurosci.org as supplemental material). Comparable accumulations with anomalous vesicle buildup were observed in other distended projections of the hippocampus (Fig. $4 b)$. In the spinal cord, ventral dystrophies were confirmed to be axonal by the observation of a surrounding thin myelin sheet (Fig. 4d,g; supplemental Fig. 2, available at www.jneurosci.org as supplemental material). These giant dystrophies had massive neurofilament accumulation with intermingled vesicles (Fig. $4 e, f)$. Similarly, smaller and more abundant ultrastructural pathologies were observed in swollen axons of ventral roots (Fig. $4 h, i)$. Thus, deletion of the KLC1 motor subunit causes early and selective axonal transport deficiencies that compound in aged KLC1-/- animals to general transport impairments observed as neuritic dystrophies, swellings, and axonal strangulation. These physical obstacles may lead to accumulation of KLC1independent cargos such as mitochondria in aged mice (supplemental Fig. 2e,f, available at www.jneurosci.org as supplemental material), causing axonal pathologies characterized by microtubule disorganization and abnormal cytoskeletal and organelle accumulations.

\section{Aberrant tau behavior and accumulation in KLC1 - / - axonopathies}

In $\mathrm{AD}$, the pathological tau behavior starts by synaptic and axonal tau protein hyperphosphorylation and microtubule destabilization in dystrophic neurites (Su et al., 1997). To test whether transport defects in aged mice leads to abnormal axonal tau phosphorylation and accumulation in KLC1-/- axonopathies, we performed immunohistochemical staining using a battery of tau antibodies in 18-month-old mice. Abnormal axonal accumulations of tau phosphorylated at Ser202 and Thr205 were observed by strong reactivity with the AT-8 antibody in ventral giant axonal dystrophies and swollen axons along roots of KLC1-/- spinal cords (Fig. 5a). Similar results were observed with another antibody against phosphorylated Ser 202 (CP13) (Fig. 5b), comparable to what is observed in $\mathrm{AD}$ and in tauopathy models (Goedert and Spillantini, 2006; McGowan et al., 2006). However, no abnormal tau was observed accumulating in neuronal cell bodies. Two conformation specific antibodies (TG3, MC1), also revealed strong staining in giant axonal dystrophies and swollen motor roots (Fig. $5 c, d$ ), suggesting that tau accumulation within those axonopathies acquired a pathological conformation similar to that found in early $\mathrm{AD}$ (Weaver et al., 2000). Equivalent abnormal tau behavior was observed with staining for later tau phosphorylation sites such as Ser396 and Ser404 (PHF1, PHF13) (supplemental Fig. 3, available at www.jneurosci.org as supplemental material). Immunoelectron microscopy using AT-8 confirmed the significant (more than threefold) abnormal density of hyperphosphorylated tau (Fig. $5 g$ ) within enlarged neurofilamentous structures of KLC1 $-/-$ giant dystrophies (Fig. 5e) and swollen roots (Fig. 5f) compared with wild-type axons. Thus, transport defects induced by KLC1 deletion result in a local abnormal phosphorylation and accumulation of tau in axons.

Increases in tau hyperphosphorylation have been suggested to affect the aggregation of tau into the NFTs found in dystrophic neurites (Ballatore et al., 2007). To test whether KLC1 transport defects increased the soluble or the insoluble tau forms, we performed cortex, brainstem, and spinal cord Sarkosyl extractions from aged mice. Although overall levels of total (Tau-5) and phosphorylated (PHF1, CP13) tau in homogenates of KLC1-/were comparable to those in wild type, soluble levels of total and phosphorylated tau were more abundant in $\mathrm{KLC1}-/-$ brainstem and spinal cord, and total insoluble forms of tau in the spinal cord were increased (supplemental Fig. $4 b$, available at www.jneurosci.org as supplemental material). Large increases in conformationally abnormal and hyperphosphorylated tau similar to those seen by immunohistochemistry were not observed. However, considering the minimal tendency of mouse tau to form abnormal filaments, and the focal nature of aberrant tau accumulations in these mutant mice, it is not surprising that we 
observed only modest overall increases in soluble and insoluble tau relative to total tau protein.

\section{Transport defects induce abnormal axonal stress kinase activation}

Neurite stress or damage may induce the activation of kinases implicated in abnormal phosphorylation of tau and neurofilaments within dystrophic neurites (Goedert et al., 1997; Reynolds et al., 1997; Lagalwar et al., 2006). In addition, the direct association of KLC1 and JNK interacting scaffold proteins (JIP1, JIP2, and JIP3/ SYD) (Bowman et al., 2000; Verhey et al., 2001) and the activation of JNK by axonal damage (Cavalli et al., 2005) suggest that transport defects could in principle lead to aberrant phosphorylation of axonal proteins. To evaluate whether JNK kinase activation occurs in response to transport defects in $K L C 1-/-$ mice, we performed quantitative Western blots from brain and spinal cord homogenates using fluorescent secondary antibodies (Fig. $6 a, b$ ). We observed a $75 \%$ increase in JNK activation by 466 and p 54 subunit phosphorylated at Thr183 and Tyr185 in KLC1-/- brain homogenates compared with wild type (Fig. $6 c, d$ ). No increase was observed in the activation of other tau-related kinases that we tested (supplemental Fig. $4 a$, available at www.jneurosci.org as supplemental material). To further test for abnormal axonal stress kinase activation caused by selective kinesin-1 transport impairments, we performed immunofluorescent staining for p-JNK. We observed a strong local activation of the axonal damage pathway as suggested by selective p-JNK accumulation in KLC1-/- axonal pathologies (Fig. 6e). Granular p-JNK staining colocalized with $\mathrm{p}$-NF diffuse accumulations in giant dys-

trophic axons and swollen motor roots (Fig. 6f). Elevated p-JNK activation assessed by punctate staining was also found associated with NFT in human AD (supplemental Fig. 5, available at www. jneurosci.org as supplemental material); consistent with previous observations in early stages of neurofibrillary pathology formation (Pei et al., 2001; Lagalwar et al., 2006). We conclude that KLC1 deletion induces the abnormal activation of JNK within axonopathies and that this aberrant kinase activity can generate abnormal cytoskeletal tau phosphorylation.

\section{Discussion}

Microtubule disassembly induced by abnormal accumulation of hyperphosphorylated tau protein and fibrillar aggregation of tau into NFTs within axons are common pathologies in several neurodegenerative dementias as well as movement disorders (Goedert and Spillantini, 2006; Ballatore et al., 2007). Axonal transport defects have been suggested as the ultimate cellular mechanism impaired by tau protein loss of function and tau toxic gain of function both in sporadic and familial tauopathies (Ballatore et al., 2007; Gasparini et al., 2007). However, the initial
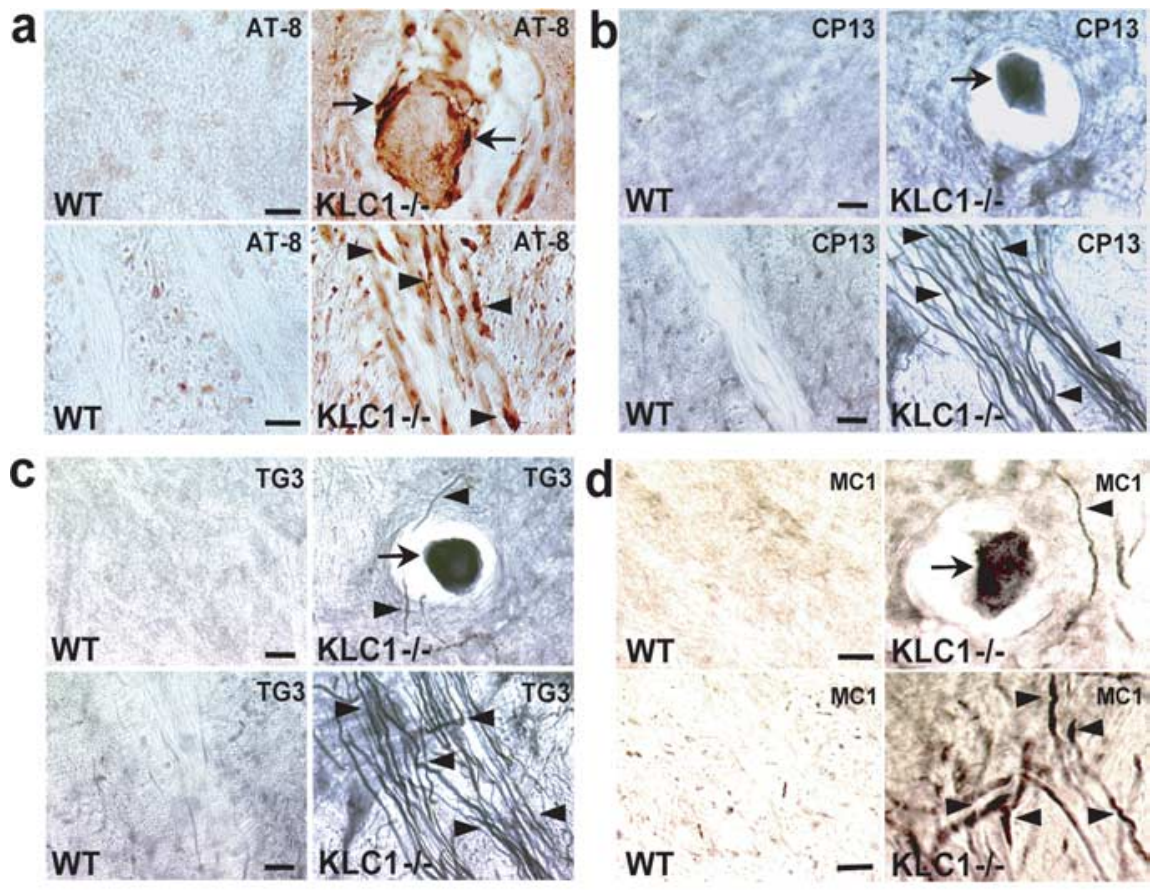

axonopathies. $\boldsymbol{a}-\boldsymbol{d}$, Eighteen-month-old WT and KLC1-/- immunohistochemistry showing tau hyperphosphorylation (AT-8, CP13; $\boldsymbol{a}, \boldsymbol{b}$ ) and conformationally abnormal tau ( (arrows) inside KLC1-/ - giant axonopathies (e) and swollen axons of ventral roots (f) Scale bars: $200 \mathrm{~nm} ; \boldsymbol{f}$ Average density quantification of immuno-gold particles $/ \mu \mathrm{m}^{2}$ from WT (black) and $K L C 1-/-$ (white) axonal roots (Student'st test; WT, $n=10 ; K L\left(1-/-, n=16\right.$; $\left.{ }^{* * *} p<0.006\right)$.

events leading to tau misbehavior remain unknown. Together, our results suggest the new hypothesis that impairments in axonal transport can lead to aberrant behavior of tau protein similar to that observed in many neurodegenerative tauopathies.

Mutations in human kinesin and dynactin genes cause transport defects and axonopathies that lead to different forms of spastic paraplegia and amyotrophic lateral sclerosis respectively (Goldstein, 2003; De Vos et al., 2008). It is interesting that depleting the KLC1 subunit of the kinesin-1 anterograde motor complex induces early and selective impairments of APP bidirectional movement, suggesting that kinesin-1 may be also involved in the regulation of axonal retrograde transport. Initial transport defects of KLC1-dependent cargos progress to general transport impairments including microtubule disruption and mitochondrial accumulation in aged dystrophic axons. In addition, significant white matter reductions in aged mutant mice revealed that axons became highly compromised upon KLC1 deletion. Interestingly, selective KLC1 transport impairments uniquely induce JNK stress kinase activation leading to abnormal tau behavior in dystrophic axons. These results represent the first report where 
a

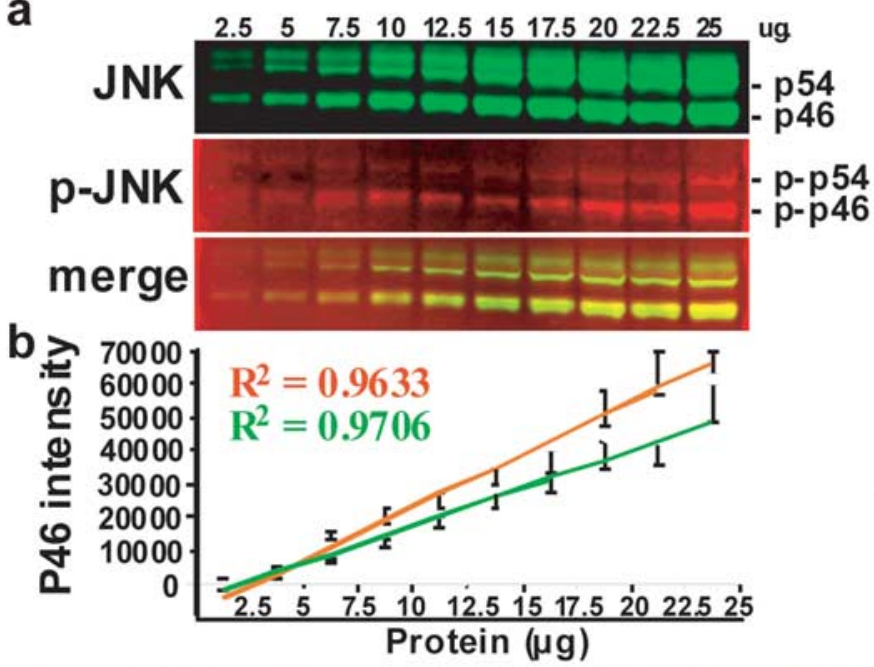

C

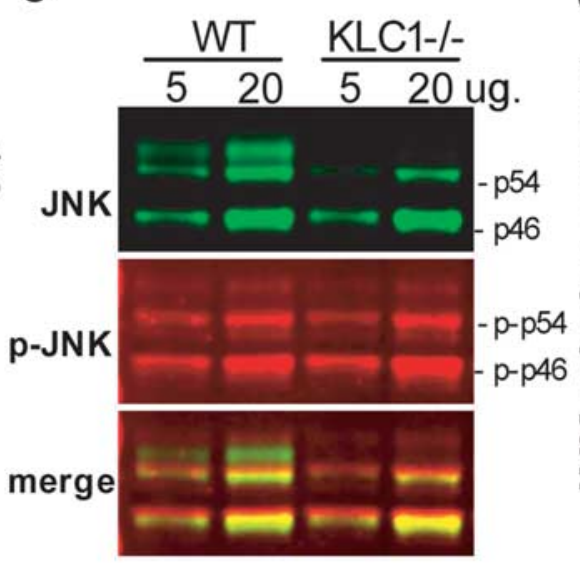

d

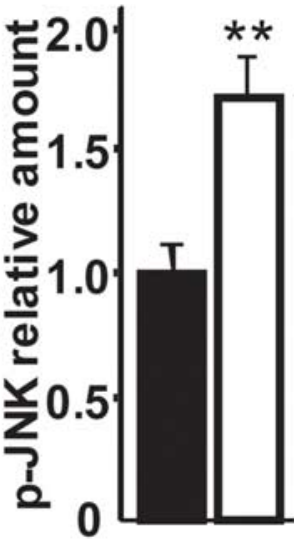

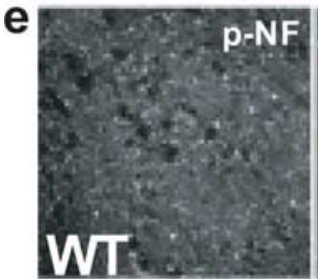
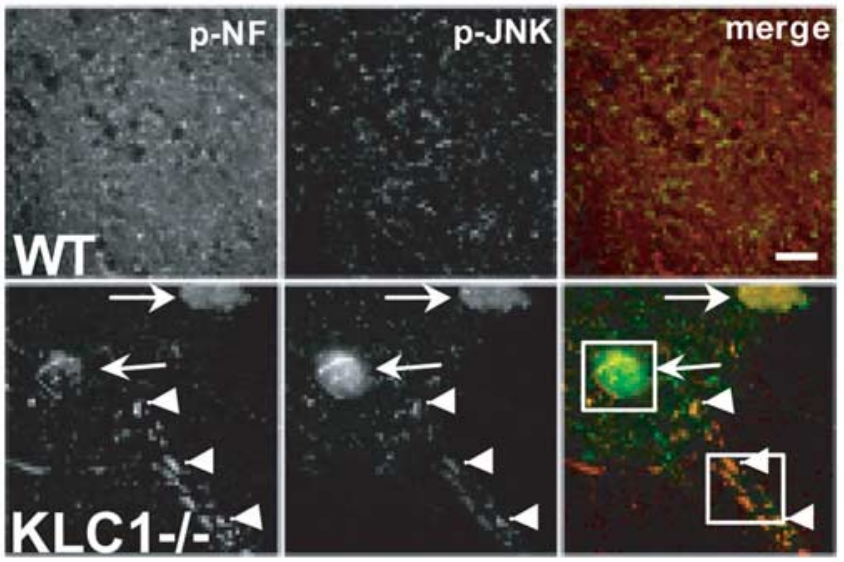
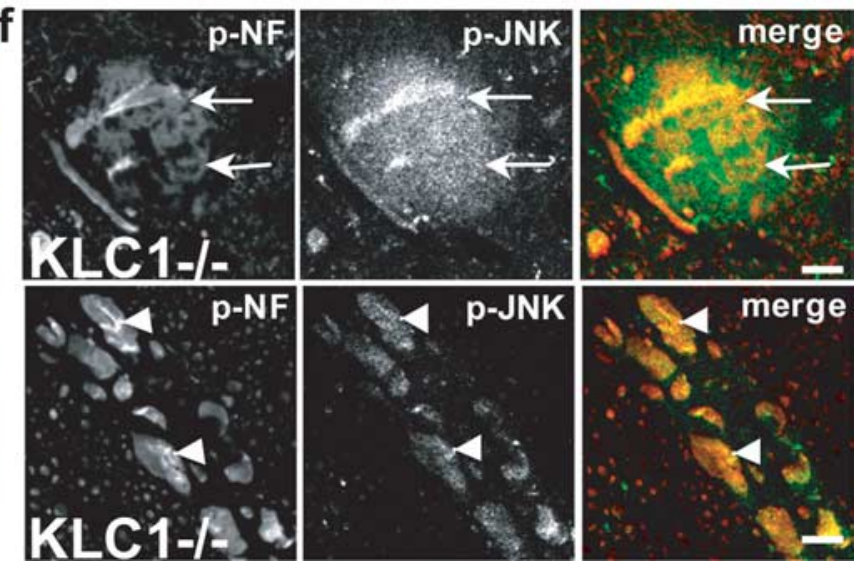

Figure 6. Increased JNK stress kinase activation in KLC1 - / - axonopathies. $\boldsymbol{a}$, Quantitative Western blots of WT brain homogenate using fluorescent secondary antibodies for JNK and p-JNK in the same membrane. $\boldsymbol{b}$, Linear regression fit $\left(R^{2}\right)$ of p 46 fluorescence intensity by protein concentration for both JNK (green) and p-JNK (red) measurements. c, Western blots of 18 -month-old total brain homogenates using fluorescent secondary antibodies. Note specific increase in p46 and p54 JNK phosphorylation in $K L C 1-/-$. $\boldsymbol{d}$, Fluorescence intensity quantification of p46 subunit phosphorylation in Western blot analyses of brain homogenates for WT (black) and KLC1-I- (white). WT p-JNK/JNK ratio was set to 1 (Student's $t$ test; $n=6$, ${ }^{* *} p<0.02$ ). $\boldsymbol{e}, \boldsymbol{f}$, Immunofluorescent staining for p-NF and p-JNK in 18-month-old ventral spinal cord regions. Axonal dystrophies (arrows) and swollen projections (arrowheads) observed in $K L C 1-/-$. Scale bar, $50 \mu \mathrm{m}$. $f$, Insets from KLC1-I- show colocalization of diffuse p-NF with punctate p-JNK staining in giant dystrophies (top) and swollen ventral projections (bottom). Scale bar, $10 \mu \mathrm{m}$.

deletion of a key motor protein subunit induces specific axonal stress kinase pathways leading to the local abnormal phosphorylation and aggregation of tau. In this context, it is interesting that human disorders involving axonal transport defects such as amyotrophic lateral sclerosis with cognitive impairment exhibit central and peripheral aggregated tau inclusion pathologies and motor neuron death similar to those observed in aged KLC1 mutant mice. (Cairns et al., 2004; Strong et al., 2006; Mackenzie, 2007; Gohar et al., 2009).

Our suggestion that transport defects can initiate the generation of tau protein abnormalities is in agreement with the recent findings showing that transport defects may be key early contributors to AD (Stokin et al., 2005). In fact, the realization that excess APP can poison the transport machinery through an A $\beta$ independent mechanism (Gunawardena and Goldstein, 2001; Stokin et al., 2008) raises the possibility that NFT initiation could also be $\mathrm{A} \beta$-independent in some circumstances. In this regard, it is striking that KLC1-deficient mice exhibit CNS white matter degeneration, prominent axonal swellings with accumulation of organelles, vesicles, and cytoskeletal components and abnormal tau hyperphosphorylation comparable to those described in $\mathrm{AD}$ (Rose et al., 2000; Higuchi et al., 2002; Xie et al., 2006). While the spinal cord phenotypes we observed in KLC1-deficient mice are not typical of CNS dementias such as $\mathrm{AD}$, the pronounced agedependent accumulation of aberrant tau and neurofilaments within spinal cord axonopathies and motor neuron degeneration are common features of transgenic mouse models overexpressing different forms of human tau (Ishihara et al., 1999; Spittaels et al., 1999; Lewis et al., 2000; Probst et al., 2000; Lin et al., 2005). This shared phenotype in mouse models may reflect species-specific differences compared with humans, but nonetheless may reveal conserved biochemical pathways induced by deficient axonal transport that lead to common mechanisms of pathology and disease development.

An additional hypothesis arising from our data point out that impairments in transport can initiate damage signaling pathways, which if chronically activated, can trigger disease mechanisms culminating in NFTs. Specifically, we found that KLC1 deletion induced early and selective transport defects of kinesin-1 cargos and increased activation of the axonal JNK stress kinase pathway, a hallmark of axonal injury (Kenney and Kocsis, 1998; Cavalli et al., 2005), and NFT formation in AD (Atzori et al., 2001; Pei et al., 2001; Lagalwar et al., 2006). Thus, cytoskeletal disorganization through JNK-mediated tau hyperphosphorylation might auto-enhance by inducing additional and severe blockages and swellings (Chang et al., 2003). 
Together, our findings that reduction of kinesin-1 function induces abnormal tau phosphorylation and conformation suggest several important conclusions. First, transport defects in neurons, in the absence of tau mutations or accumulation of $A \beta$ or other neurotoxic agents, are sufficient to initiate biochemical pathways that can culminate in pathological accumulation of tau. Second, APP-induced transport defects may be capable of generating aberrant tau protein behavior in $\mathrm{A} \beta$-independent pathways. Third, the finding that kinesin-1 transport defects have phenotypic effects comparable to APP, presenilin, and tau (Goldstein, 2003; Stokin and Goldstein, 2006) suggest that these genes affect common transport pathways that when altered can lead to neurodegenerative diseases such as AD.

In light of these results, we propose a testable model in which defects in axonal transport can lead to activation of axonal stress kinase pathways, which increase the phosphorylation states of cytoskeletal proteins such as tau and NF. If this activation is chronic, human tau protein may ultimately form NFTs that further impair axonal transport by disrupting the microtubule network and blocking axonal highways, launching an autocatalytic spiral culminating in neurodegeneration. Thus, early axonal transport defects in $\mathrm{AD}$ and related tauopathies may share a common mechanism that ultimately will give rise to compromised synapse function and neurodegeneration.

\section{References}

Araki Y, Kawano T, Taru H, Saito Y, Wada S, Miyamoto K, Kobayashi H, Ishikawa HO, Ohsugi Y, Yamamoto T, Matsuno K, Kinjo M, Suzuki T (2007) The novel cargo Alcadein induces vesicle association of kinesin-1 motor components and activates axonal transport. EMBO J 26:1475-1486.

Atzori C, Ghetti B, Piva R, Srinivasan AN, Zolo P, Delisle MB, Mirra SS, Migheli A (2001) Activation of the JNK/p38 pathway occurs in diseases characterized by tau protein pathology and is related to tau phosphorylation but not to apoptosis. J Neuropathol Exp Neurol 60:1190-1197.

Ballatore C, Lee VM, Trojanowski JQ (2007) Tau-mediated neurodegeneration in Alzheimer's disease and related disorders. Nat Rev Neurosci 8:663-672.

Barghorn S, Zheng-Fischhöfer Q, Ackmann M, Biernat J, von Bergen M, Mandelkow EM, Mandelkow E (2000) Structure, microtubule interactions, and paired helical filament aggregation by tau mutants of frontotemporal dementias. Biochemistry 39:11714-11721.

Bowman AB, Kamal A, Ritchings BW, Philp AV, McGrail M, Gindhart JG, Goldstein LS (2000) Kinesin-dependent axonal transport is mediated by the sunday driver (SYD) protein. Cell 103:583-594.

Buée L, Bussière T, Buée-Scherrer V, Delacourte A, Hof PR (2000) Tau protein isoforms, phosphorylation and role in neurodegenerative disorders. Brain Res Brain Res Rev 33:95-130.

Cairns NJ, Lee VM, Trojanowski JQ (2004) The cytoskeleton in neurodegenerative diseases. J Pathol 204:438-449.

Cavalli V, Kujala P, Klumperman J, Goldstein LS (2005) Sunday Driver links axonal transport to damage signaling. J Cell Biol 168:775-787.

Chang L, Jones Y, Ellisman MH, Goldstein LS, Karin M (2003) JNK1 is required for maintenance of neuronal microtubules and controls phosphorylation of microtubule-associated proteins. Dev Cell 4:521-533.

De Vos KJ, Grierson AJ, Ackerley S, Miller CC (2008) Role of axonal transport in neurodegenerative diseases. Annu Rev Neurosci 31:151-173.

Dixit R, Ross JL, Goldman YE, Holzbaur EL (2008) Differential regulation of dynein and kinesin motor proteins by tau. Science 319:1086-1089.

Duerstock BS, Bajaj CL, Borgens RB (2003) A comparative study of the quantitative accuracy of three-dimensional reconstructions of spinal cord from serial histological sections. J Microsc 210:138-148.

Gasparini L, Terni B, Spillantini MG (2007) Frontotemporal dementia with tau pathology. Neurodegener Dis 4:236-253.

Glater EE, Megeath LJ, Stowers RS, Schwarz TL (2006) Axonal transport of mitochondria requires milton to recruit kinesin heavy chain and is light chain independent. J Cell Biol 173:545-557.

Goedert M, Spillantini MG (2006) A century of Alzheimer's disease. Science 314:777-781.
Goedert M, Hasegawa M, Jakes R, Lawler S, Cuenda A, Cohen P (1997) Phosphorylation of microtubule-associated protein tau by stressactivated protein kinases. FEBS Lett 409:57-62.

Gohar M, Yang W, Strong W, Volkening K, Leystra-Lantz C, Strong MJ (2009) Tau phosphorylation at threonine-175 leads to fibril formation and enhanced cell death: implications for amyotrophic lateral sclerosis with cognitive impairment. J Neurochem 108:634-643.

Goldstein LS (2003) Do disorders of movement cause movement disorders and dementia? Neuron 40:415-425.

Gunawardena S, Goldstein LS (2001) Disruption of axonal transport and neuronal viability by amyloid precursor protein mutations in Drosophila. Neuron 32:389-401.

Hanger DP, Betts JC, Loviny TL, Blackstock WP, Anderton BH (1998) New phosphorylation sites identified in hyperphosphorylated tau (paired helical filament-tau) from Alzheimer's disease brain using nanoelectrospray mass spectrometry. J Neurochem 71:2465-2476.

Higuchi M, Lee VM, Trojanowski JQ (2002) Tau and axonopathy in neurodegenerative disorders. Neuromolecular Med 2:131-150.

Hollenbeck PJ, Saxton WM (2005) The axonal transport of mitochondria. J Cell Sci 118:5411-5419.

Hutton M, Lendon CL, Rizzu P, Baker M, Froelich S, Houlden H, PickeringBrown S, Chakraverty S, Isaacs A, Grover A, Hackett J, Adamson J, Lincoln S, Dickson D, Davies P, Petersen RC, Stevens M, de Graaff E, Wauters E, van Baren J, et al. (1998) Association of missense and 5'-splice-site mutations in tau with the inherited dementia FTDP-17. Nature 393:702-705.

Ishihara T, Hong M, Zhang B, Nakagawa Y, Lee MK, Trojanowski JQ, Lee VM (1999) Age-dependent emergence and progression of a tauopathy in transgenic mice overexpressing the shortest human tau isoform. Neuron 24:751-762.

Kaether C, Skehel P, Dotti CG (2000) Axonal membrane proteins are transported in distinct carriers: a two-color video microscopy study in cultured hippocampal neurons. Mol Biol Cell 11:1213-1224.

Kamal A, Stokin GB, Yang Z, Xia CH, Goldstein LS (2000) Axonal transport of amyloid precursor protein is mediated by direct binding to the kinesin light chain subunit of kinesin-I. Neuron 28:449-459.

Kenney AM, Kocsis JD (1998) Peripheral axotomy induces long-term c-Jun amino-terminal kinase- 1 activation and activator protein-1 binding activity by c-Jun and junD in adult rat dorsal root ganglia in vivo. J Neurosci $18: 1318-1328$.

Koo EH, Sisodia SS, Archer DR, Martin LJ, Weidemann A, Beyreuther K, Fischer P, Masters CL, Price DL (1990) Precursor of amyloid protein in Alzheimer disease undergoes fast anterograde axonal transport. Proc Natl Acad Sci U S A 87:1561-1565.

Lagalwar S, Guillozet-Bongaarts AL, Berry RW, Binder LI (2006) Formation of phospho-SAPK/JNK granules in the hippocampus is an early event in Alzheimer disease. J Neuropathol Exp Neurol 65:455-464.

Lewis J, McGowan E, Rockwood J, Melrose H, Nacharaju P, Van Slegtenhorst M, Gwinn-Hardy K, Paul Murphy M, Baker M, Yu X, Duff K, Hardy J, Corral A, Lin WL, Yen SH, Dickson DW, Davies P, Hutton M (2000) Neurofibrillary tangles, amyotrophy and progressive motor disturbance in mice expressing mutant (P301L) tau protein. Nat Genet 25:402-405.

Lin WL, Zehr C, Lewis J, Hutton M, Yen SH, Dickson DW (2005) Progressive white matter pathology in the spinal cord of transgenic mice expressing mutant (P301L) human tau. J Neurocytol 34:397-410.

Long JM, Mouton PR, Jucker M, Ingram DK (1999) What counts in brain aging? Design-based stereological analysis of cell number. J Gerontol A Biol Sci Med Sci 54:B407-B417.

Mackenzie IR (2007) The neuropathology of FTD associated with ALS. Alzheimer Dis Assoc Disord 21:S44-S49.

McGowan E, Eriksen J, Hutton M (2006) A decade of modeling Alzheimer's disease in transgenic mice. Trends Genet 22:281-289.

Mouton PR (2002) Principles and practices of unbiased stereology. Baltimore, MD: John Hopkins UP.

Nacharaju P, Lewis J, Easson C, Yen S, Hackett J, Hutton M, Yen SH (1999) Accelerated filament formation from tau protein with specific FTDP-17 missense mutations. FEBS Lett 447:195-199.

Pei JJ, Braak E, Braak H, Grundke-Iqbal I, Iqbal K, Winblad B, Cowburn RF (2001) Localization of active forms of C-jun kinase (JNK) and p38 kinase in Alzheimer's disease brains at different stages of neurofibrillary degeneration. J Alzheimers Dis 3:41-48.

Probst A, Götz J, Wiederhold KH, Tolnay M, Mistl C, Jaton AL, Hong M, 
Ishihara T, Lee VM, Trojanowski JQ, Jakes R, Crowther RA, Spillantini MG, Bürki K, Goedert M (2000) Axonopathy and amyotrophy in mice transgenic for human four-repeat tau protein. Acta Neuropathol 99:469-481.

Rahman A, Kamal A, Roberts EA, Goldstein LS (1999) Defective kinesin heavy chain behavior in mouse kinesin light chain mutants. J Cell Biol 146:1277-1288.

Reynolds CH, Utton MA, Gibb GM, Yates A, Anderton BH (1997) Stressactivated protein kinase/c-jun N-terminal kinase phosphorylates tau protein. J Neurochem 68:1736-1744.

Rose SE, Chen F, Chalk JB, Zelaya FO, Strugnell WE, Benson M, Semple J, Doddrell DM (2000) Loss of connectivity in Alzheimer's disease: an evaluation of white matter tract integrity with colour coded MR diffusion tensor imaging. J Neurol Neurosurg Psychiatry 69:528-530.

Rovelet-Lecrux A, Hannequin D, Raux G, Le Meur N, Laquerrière A, Vital A, Dumanchin C, Feuillette S, Brice A, Vercelletto M, Dubas F, Frebourg T, Campion D (2006) APP locus duplication causes autosomal dominant early-onset Alzheimer disease with cerebral amyloid angiopathy. Nat Genet 38:24-26.

Spillantini MG, Murrell JR, Goedert M, Farlow MR, Klug A, Ghetti B (1998) Mutation in the tau gene in familial multiple system tauopathy with presenile dementia. Proc Natl Acad Sci U S A 95:7737-7741.

Spittaels K, Van den Haute C, Van Dorpe J, Bruynseels K, Vandezande K, Laenen I, Geerts H, Mercken M, Sciot R, Van Lommel A, Loos R, Van Leuven F (1999) Prominent axonopathy in the brain and spinal cord of transgenic mice overexpressing four-repeat human tau protein. Am J Pathol 155:2153-2165.

Stamer K, Vogel R, Thies E, Mandelkow E, Mandelkow EM (2002) Tau blocks traffic of organelles, neurofilaments, and APP vesicles in neurons and enhances oxidative stress. J Cell Biol 156:1051-1063.

Stokin GB, Goldstein LS (2006) Axonal transport and Alzheimer's disease. Annu Rev Biochem 75:607-627.
Stokin GB, Lillo C, Falzone TL, Brusch RG, Rockenstein E, Mount SL, Raman R, Davies P, Masliah E, Williams DS, Goldstein LS (2005) Axonopathy and transport deficits early in the pathogenesis of Alzheimer's disease. Science 307:1282-1288.

Stokin GB, Almenar-Queralt A, Gunawardena S, Rodrigues EM, Falzone T, Kim J, Lillo C, Mount SL, Roberts EA, McGowan E, Williams DS, Goldstein LS (2008) Amyloid precursor protein-induced axonopathies are independent of amyloid-beta peptides. Hum Mol Genet 17:3474-3486.

Strong MJ, Yang W, Strong WL, Leystra-Lantz C, Jaffe H, Pant HC (2006) Tau protein hyperphosphorylation in sporadic ALS with cognitive impairment. Neurology 66:1770-1771.

Su JH, Deng G, Cotman CW (1997) Transneuronal degeneration in the spread of Alzheimer's disease pathology: immunohistochemical evidence for the transmission of tau hyperphosphorylation. Neurobiol Dis 4:365-375.

Teipel SJ, Bayer W, Alexander GE, Bokde AL, Zebuhr Y, Teichberg D, MüllerSpahn F, Schapiro MB, Möller HJ, Rapoport SI, Hampel H (2003) Regional pattern of hippocampus and corpus callosum atrophy in Alzheimer's disease in relation to dementia severity: evidence for early neocortical degeneration. Neurobiol Aging 24:85-94.

Verhey KJ, Meyer D, Deehan R, Blenis J, Schnapp BJ, Rapoport TA, Margolis B (2001) Cargo of kinesin identified as JIP scaffolding proteins and associated signaling molecules. J Cell Biol 152:959-970.

Weaver CL, Espinoza M, Kress Y, Davies P (2000) Conformational change as one of the earliest alterations of tau in Alzheimer's disease. Neurobiol Aging 21:719-727.

Xie S, Xiao JX, Gong GL, Zang YF, Wang YH, Wu HK, Jiang XX (2006) Voxel-based detection of white matter abnormalities in mild Alzheimer disease. Neurology 66:1845-1849.

Yoshida H, Hastie CJ, McLauchlan H, Cohen P, Goedert M (2004) Phosphorylation of microtubule-associated protein tau by isoforms of c-Jun N-terminal kinase (JNK). J Neurochem 90:352-358. 